ISBN 978-93-86878-06-9

$11^{\text {th }}$ International Conference on Building Design, Civil, Materials and Transportation Engineering

(BDCMTE-17)

Kuala Lumpur (Malaysia) Dec. 14-15, 2017

\title{
Implication of Intelligent Transport Systems for the Prevention of Road and Rail Accidents to Great Extent
}

\author{
Manmohan Singh \\ Lovely Professional University
}

\begin{abstract}
Road safety is the concerning issue in the today's scenario in many of the developing, underdeveloped as well as in some of the developed nations. A global status report on road safety published by World Health Organization (WHO) in 2015 showcases that 1.25 million people die every year due to road accidents. The report also predicts that by 2020 road accidents will be the 3rd greatest cause of death which will rise from 1.2 to 2 million people annually in the coming years. On the 10th May 2010, the general assembly of United Nations adopted a resolution which proclaimed that the period 2011-2020 as the Decade of Action for road safety. Wireless Communications Systems are now being deployed in vehicles in a number of different ways. Cellular communication technology is already playing a large role in fleet management applications and vehicle monitoring. In addition, Dedicated Short Range Communication (DSRC) radios will likely be deployed to enable vehicle-to-vehicle, vehicle to infrastructure and infrastructure-to-vehicle applications that are primarily focused on improving safety. However, road safety issue can take the advantage of wireless communications applications which will emerge into the "connected vehicle" technology. This research paper aims towards the road safety as roads accidents are $\mathbf{1 0 0}$ percent preventable and how this can be achieved through implication of ITS.
\end{abstract}

Keywords: Road safety, Intelligent Transport System, Wireless Communications

\section{Introduction}

Road safety is an important concern today. A global status report on road safety 2015 by WHO reveal that about 1.25 million people die every year as a result of road accidents and about $91 \%$ of world fatalities on the roads occur in low income and middle income countries where as these countries cater only half of the world's vehicles. In the report WHO predicts that by 2020 road accidents will be the 3rd greatest cause of death which will rise from 1.2 to 2 million people annually.(1) The fact which cannot be denied is that Road accidents are $100 \%$ preventable. The plateau in road traffic deaths, set against a $4 \%$ increase in global population and $16 \%$ increase in motorization,suggests that road safety effects over the past 3 years have saved lives. In the last 3 years 17 countries representing 409 million people have amended their laws on one or more key risk factors for the road traffic injuries to bring them into line with best practices of the world (2). On the 10th may 2010 , the UNO general assembly adopted resolution with which it proclaimed the period 2011-2020 as the decade of action for road safety, with a goal to stabilize and the to reduce the forecast level of road traffic fatalities around the world by increasing activities conducted at the national regional and global levels. One of the main findings repeatedly found everywhere was that $85-90 \%$ of accidents are caused by human factors. (3) The only way to avoid these accidents is that if there can be a mechanism to alter the drivers which is approaching danger. This can be achieved by the Intelligent Transport Systems. ITS can play a great role in improving the transportation performance by five ways such as safety, productivity, energy, mobility and environment .Safety is measured performance trough changes in crash rates or different surrogate measures like vehicle speed ,traffic law violation and traffic conflicts. Driver critical reason was further analysised by the National Motor Vehicle Crash 
Causation Survey (NMVCCS) in ( 2005-2007) and found that around 41 percentage is recognition error and around 33 percentage is decision error, the performance error was around 11 percentage and non -performance error including sleep were 7 percentage and other factors were 8 percentage. These all errors can and addressed bt the Intelligent Transport Systems.

'Driver related Critical Reasons

\begin{tabular}{|l|l|l|}
\hline Critical Reason & Estimated (Based on 94\% of the NMVCCS crashes) \\
\cline { 2 - 3 } & Number & $\begin{array}{l}\text { Percentage* } \\
\pm 95 \% \text { conf. limits }\end{array}$ \\
\hline Recognition Error & & $41 \% \pm 2.2 \%$ \\
\hline Decision Error & 845,000 & $33 \% \pm 3.7 \%$ \\
\hline Performance Error & 684,000 & $11 \% \pm 2.7 \%$ \\
\hline Non-Performance Error (sleep, etc.) & 210,000 & $7 \% \pm 1.0 \%$ \\
\hline Other & 145,000 & $8 \% \pm 1.9 \%$ \\
\hline Total & 162,000 & $100 \%$ \\
\hline
\end{tabular}

* Percentages are based on unrounded estimated frequencies

(Data Source: NMVCCS 2005-2007)

The deaths caused by the road crashes can be prevented. As taking the case of car crashes in United States .The data released by the US Department of transport that 21,000 of the annual 43,000 road accident deaths in the US are caused by roadway departures and intersection-related incidents. (3)This can be prevented by implementing various ITS applications \& measures such as vehicle-to-vehicle, vehicle to infrastructure and infrastructure-tovehicle.

\section{Various Applications in ITS for the Road \& Rail Accident Prevention}

\subsection{Vehicle to Vehicle}

Identified the forward collision avoidance (FCA) as a safety application for development. Development has been launched by five original equipment manufacturers (OEMs). Each OEM will include control after warning as a means to avoid forward collision crashes. To date, FCA performance measures have been completed. (6)

\subsection{Connected Vehicle Safety for Rail}

Connected Vehicle Safety for Rail is a research effort designed to support the Rail Safety Improvement Act of 2008, which mandates that certain classes of railroads that carry Toxic Inhalation or Poison Inhalation (TIH/PIH) cargo have categories of track instrumented with Positive Train Control (PTC) by 2015. (7)

The vision for the Connected Vehicle Safety for Rail is to research and demonstrate a prototype set of applications to advance the FRA's safety goal of a reduction in fatalities, injuries, and collisions, as well as to identify a cohesive approach to fulfilling other goals such as reduction of transportation congestion. A further focus of the research is to develop a more precise understanding of the risks presented by the railroad Right of Way (ROW) and to determine how best to mitigate these risks through the application of ITS technologies. (7)

\subsection{Vehicle to Infrastructure}

V2I Communications for Safety is the wireless exchange of critical safety and operational data between vehicles and highway infrastructure, intended primarily to avoid motor vehicle crashes and enable a wide range of other safety, mobility, and environmental benefits. (8) Preliminary studies show that an additional 12 percent of potential crash scenarios could be addressed by V2I safety applications. The vision for the V2I research is to enable safety applications that are designed to avoid or mitigate vehicle crashes (inclusive of automobiles, trucks, motor coaches, and transit vehicles), particularly for those crash scenarios not addressed by V2V research.(8)

There are several sensor system is developed to prevent road accidents. There is a sensor system driving control device available which helps drivers to avoid accidents by detecting the presence of nearby vehicles, motorcycles and people and by controlling the driving speed and distance to other vehicles. Another type of sensor is Warning system for mechanical problems. This gives warning that the vehicle condition is poor and 
need maintenance. The blind area warning system gives drivers caution while car is taking turn or backing and Anti-lock breaking system (ABS) prevent the car from skidding.(3) There is another system for drivers namely Warning (avoidance) system for driver's danger. While driver is sleeping or drunk then bell will ring and in extreme case will stop the car.

Seat belts, Airbags and Easy-to-use vehicles enhance the performance of seat belts and airbags to mitigate accidents. For mitigation of pedestrian's injury there is a sensor which called airbags for pedestrian protection, and this can detect and operate in the instance of pedestrian collision. (3)

Shock absorption system is important about the prevention of serious accidents by analyzing a mechanism to stop vehicles sliding under a large truck or overturning during accidents. (5)Automatic mayday system and automatic fire extinguisher is being carried out automatic notification to the police and fire station, and also automatic fire extinguishing when an accident occurs.(3)

\subsection{Positive Train Control}

This system works with the GPS and transmitters. Before the train departs the travel information is transmitted to the onboard computer. GPS track the position of the train then wayside units along the track send switch alignment and signalling information back to the system. As the train moves, the system calculates a safe braking curve. If the engineer does not stop the train, the computer system is supposed to automatically stop the train. Positive train control helps in preventing certain types of accidents such as a train derailing due to excessive speed. A train running through a misaligned switch. A train colliding with another train. A train travelling into a work zone.

\section{Importance of ITS Architecture}

The traditional meaning of the term "architecture" is related to the design of buildings and other physical structures. In modern times however the term has a broader meaning and is used to mean the planning \& design of any kind of system. This is especially true in the case of complex systems that have many interrelated parts, which put together to work in an integrated manner to fulfill a common objective. ITS is a complex system; so it is common to see the term "architecture" used with ITS. ITS architecture defines a framework within which a system can be planned, designed and built. Intelligent transportation system (ITS) is interrelated systems that work together to deliver transportation services. Integration of these systems requires architecture to illustrate to arrive at a consensus on the approach to be taken by a group of stakeholders regarding their particular systems. An ITS architecture defines the systems that allows to interface and interconnect with various sub systems relating to the flow of information exchanges between these sub-systems.

\section{Conclusion}

Automated highway is not yet realizable but nevertheless is an important application. In these highways the vehicles are able to cruise without help of their drivers. We need the system on the roads to lead cars safely with devices and antennas to send that receive information and signals about the condition of traffic and roads. Recently, useful automotive navigation systems have been evolving. In the future, they may direct us to the shortest way to our destination by avoiding traffic congestion and accidents. This is done by cooperation between vehicles. For example each vehicle knows the speed and direction of travel of its neighboring vehicles through communication with them. The status is updated frequently; therefore each vehicle can predict the future up to some necessary time and is able to make appropriate decisions in appropriate time. Because automated highways are not limited by human response time, much higher speeds with very low accidents will be possible. As it was found in the literature review that 80 to 90 percent accidents are caused by human errors so with the implication of various Intelligent Transportations Systems applications these accidents can be prevented to a greater extent. 


\section{References}

[1] Global Status Report On Road Safety by World Health Organization Department of Violence \& Injury Prevention \& Disability (VIP) 20 Avenue Appia Geneva 27 Switzerland

[2] Des McKibbin ,Examining Best Practice in Road Safety Management

[3] T.M. Muruganı, Dr.M.Kandasamy,G.Revathy, Accident Prevention System Through ( ISSN: 2349 - 9362 ) SSRG International Journal of Industrial Engineering (SSRG-IJIE) - volume 4 Issue 1 - Jan to Feb 2017

[4] P.K SARKAR, A.K JAINA. Intelligent Transport Systems PHI Learning Pvt. Ltd., 15-Nov-2017, New Delhi.

[5] P. Salmi, M. Torkkeli , Inventions Utilizing Satellite Navigation Systems in the Railway Satellite Navigation Syatems in the Railway Industry - An Analysis of Patenting Activity.

[6] https://www.its.dot.gov/research_archives/safety/v2v_comm_progress.htm

[7] https://www.its.dot.gov/research_archives/safety/safety_rail.htm

[8] https://www.its.dot.gov/research archives/safety/v2i_comm_safety.htm 